\title{
Dutch Reduction Domains: Between Syllables and Feet
}

\author{
Aleksei Nazarov \\ University of Massachusetts, Amherst
}

\section{Introduction}

Since the introduction of metrical categories (Selkirk 1980), the metrical foot has been acknowledged as a separate, designated level in prosodic trees (Liberman \& Prince 1977). Recently, however, it has been argued by Martínez-Paricio (2013), Bennett (2013), and Kager \& Martínez-Paricio (2014) that the metrical foot can be recursive, which has the practical consequence that the Minimal Foot and the Maximal Foot are two separate (although co-dependent) levels available to the grammar (see (1a)). In this paper, I will argue that in addition to a Minimal and Maximal Foot level, Standard Dutch provides evidence for yet another level of prosodic tree structure between the syllable and the Prosodic Word (as shown in (1b)). I will call this level the Reduction Domain because of its intimate connection to vowel reduction (see section 3).

(1) Different versions of the prosodic hierarchy inside a single word

a. Prosodic Word $>$ Maximal Foot $>$ Minimal Foot $>$ Syllable

b. Prosodic Word $>$ (Maximal Foot $>$ Minimal) Foot $>$ Reduction Domain $>$ Syllable

In this fashion, this paper calls for a closer look at the structure of the prosodic tree, by asking if there could be "microprojections" between the foot and the syllable, as well as between the foot and the Prosodic Word. I propose a level that comes in between feet and syllables: the Reduction Domain (RD) - a domain which has a full vowel syllable as its head, and has a potential dependent in the form of a schwa syllable, as shown in (2). This structure can be traced back to an idea put forward by van der Hulst \& Moortgat (1980), although in a different framework of analysis (their theory will be briefly discussed in section 2).

(2) Structure of the Reduction Domain (RD)

$<$ full vowel syllable. (schwa vowel syllable) $>$

Examples: $<$ laks $>$ 'slack', $<$ bi tor $>$ 'bitter'

The arguments for this structure come from two seemingly disjoint phenomena in Dutch phonology. One is the structure of native verb and adjective stems. Trommelen (1989) has observed that such stems in Dutch consist of a full vowel syllable, optionally followed by a schwa syllable - a template which calls for an explanation; an account which involves Reduction Domains appears most elegant.

The second phenomenon is vowel reduction. It has long been observed (Kager 1989, van Oostendorp 1995, Booij 1995) that vowel reduction in Dutch is sensitive to rhythmical considerations. I will offer an account of this phenomenon in terms of Reduction Domains, in which the rhythmical restriction on vowel reduction in Dutch falls out from the Stress-to-Weight Principle (Prince 1990, Gouskova 2003:90 and references cited there). I will argue that this account has several conceptual advantages over existing accounts, and makes empirical predictions which can be tested in future work.

There are several ways to contextualize the Reduction Domain in a universal theory of prosodic domains, which I will briefly review in section 4. In my analysis, I will treat the Reduction Domain as a unit which can be present or absent in a particular language, but more research needs to be done to determine the proper theoretical status of Reduction Domains.

\footnotetext{
* Special thanks to John McCarthy and Marc van Oostendorp for substantial discussion of and comments on this work. Many thanks also to Adam Albright, Jan Don, David Erschler, Ben Hermans, René Kager, Michael Kenstowicz, Kathrin Linke, Claire Moore-Cantwell, Joe Pater, Gertjan Postma, Robert Staubs, Donca Steriade, Kristine Yu, and Kie Zuraw for very helpful discussion and comments, as well as to audiences at TABUdag 2009 (University of Groningen), NELS 45 (MIT), and at Leiden University, the Meertens Instituut, and the University of Massachusetts, Amherst. All errors are mine.
}

(C) 2015 Aleksei Nazarov

Proceedings of AMP 2014

Completed March 11, 2015 
The rest of this paper will be structured as follows: section 2 will discuss the evidence for Reduction Domains from Dutch morphotactics, section 3 will present my analysis of vowel reduction, and, finally, section 4 will offer concluding remarks.

\section{Morphotactics}

Trommelen (1989) surveyed the morphotactics of underived stems of different lexical categories in Dutch. One of her most important conclusions is that underived verb and adjective stems almost never contain more than one full vowel, as opposed to nouns. Canonical (underived) verb and adjective stems have the shape of a full vowel syllable, optionally followed by a schwa syllable:

$\begin{array}{ll}{ }^{\sigma} \sigma & (\sigma) \\ \text { full vowel } & \text { schwa } \\ \text { nucleus } & \text { nucleus }\end{array}$

Trommelen (1989) argues that the requirement on verb and adjective stems in Dutch is that they be monosyllabic at the underlying level, and that the schwa is epenthetic. This is because all verbs and adjective stems that end in a schwa syllable end in an obstruent-schwa-sonorant sequence, and Trommelen assumes that word-final obstruent-sonorant clusters are broken up by epenthetic schwa.
(4) a. obstruent-obstruent final
/laks- $\rightarrow$ [laks-] 'slack'
b. obstruent-sonorant final (/r/is a sonorant; Booij 1995)
$/$ vext- $\rightarrow$ [vext-] 'fight (verb)'
/bitr-/ $\rightarrow$ [bitor-] 'bitter'
$/$ stotr- $/ \rightarrow$ [stotər-] 'stutter (verb)'

Don \& Erkelens (2006) confirm the psychological reality of Trommelen's idea that verb and adjective roots cannot have more than one full vowel. They report the results of an experiment in which subjects were asked to categorize a series of non-words as verbs or nouns, where the non-words were either monosyllabic, or disyllabic with full vowels in each syllable. The non-words which had two full vowels had a strong tendency to be categorized as nouns and not verbs, whereas the non-words that were monosyllabic were categorized as verbs and nouns at chance. This indicates that there is somehow a strong dispreference of underived verb stems with more than one full vowel.

Unfortunately, Don \& Erkelens did not have stimuli that had a full vowel syllable followed by a schwa syllable. Had such stimuli been included, then it could have been investigated whether it is essential that the schwa in the second syllable of a verb or adjective stem be followed by a sonorant, or not. Since this empirical evidence is lacking, I will assume that the restriction on verb and adjective roots is just the one stated in (3): it may not be larger than a full vowel syllable plus a schwa syllable.

It is true that verb and adjective stems almost always end in a consonant, as noted by Trommelen. However, this fact could be explained as an effect of paradigmatic pressure (McCarthy 2005): verbs and adjectives must occur with affixes that start in a vowel, while this is not the case for nouns (Booij 2002). Although an extended account along these lines lies outside the scope of this paper, I will assume that the consonant-finality of verb and adjective roots has an explanation separate from the fact that they may not have more than one full vowel.

Trommelen's (1989) analysis of verb and adjective roots' being underlyingly monosyllabic, though quite appealing, cannot be incorporated into Optimality Theory (Prince \& Smolensky 1993/2004; OT), since OT does not allow constraints that restrict underlying forms. In other words, a constraint like "the underlying form of a verb or adjective roots must fit into one syllable" is not acceptable, and the idea that disyllabic verb/adjective roots like the ones in (4b) have an epenthetic vowel cannot salvage the monosyllabicity analysis. Any OT account must rely on the surface shape of verb and adjective roots to compute their acceptability.

Since verb and adjective roots may exceed one syllable on the surface (see (4b)), the surfacce constraint on the shape of these roots cannot be that verb and adjective stems must fit into a syllable. It would also not suffice to state that verb and adjective roots must fit into a foot (see (5)), since Dutch feet are allowed to have full vowel syllables as dependents (Kager 1989, van Oostendorp 1995, 1997a and references cited there). 
(5) Since a foot allows full vowel dependents, noun roots as well as verb or adjective roots fit into a foot ('bi.tor) 'bitter': fits into one foot, and is a well-formed adjective root

('sa.li) 'sage (herb)': fits into one foot, but is only well-formed as a noun, NOT as a verb or adjective root

I propose here that the unit to which a verb or adjective root in Dutch must conform lies in between the syllable and the foot: a Reduction Domain (RD). I define Reduction Domains as prosodic domains which have syllables with full vowel nuclei as their heads, and syllables with schwa as their dependents. For Dutch, such domains must be left-headed (since verb and adjectives consist of a full vowel syllable followed by an optional schwa syllable, not the other way around).

(6)

a. The Reduction Domain (RD)

Head: full vowel syllable Dutch: $<$ Head (Dependent) $>$

Dependent (optional): schwa syllable examples: $<$ bi tər $>,<$ laks $>$

b. Constraint on verb/adjective morphotactics

Verb/Adj-Root $=<>_{\mathrm{RD}}$

The idea of the Reduction Domain is very similar to an idea put forth earlier by van der Hulst \& Moortgat (1980:23) that < full vowel + schwa $>$ forms its own foot domain, which recurs inside a larger domain which indicates stress (this analysis is only sketched in example (43) of that paper; in the examples below, I indicate the foot as $\Sigma$, according to van der Hulst \& Moortgat's own usage, and the larger domain is indicated as $\left.\Sigma^{\prime}\right)$.

(7) Two words footed according to van der Hulst \& Moortgat's (1980) assumptions ( $\Sigma$ stands for a foot)

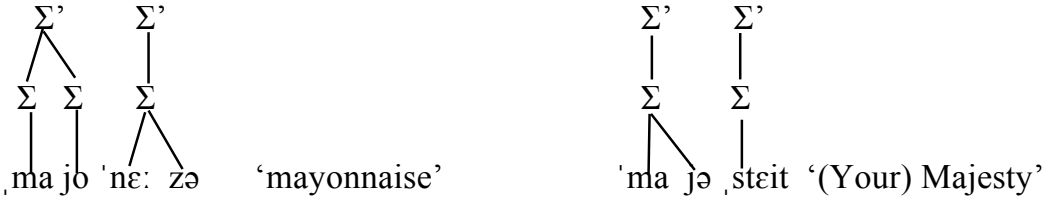

This representation is reminiscent of recursive foot structures. However, recent work on foot recursivity shows that it is very unlikely that the Reduction Domain is a foot embedded inside another foot. MartínezParicio (2013) and Kager \& Martínez-Paricio (2014) have proposed arguments for recursive feet in Dutch, in which the head of every foot, whether it be embedded or non-embedded, contains a stressed syllable.

In particular, Kager \& Martínez-Paricio (2014) show that the presence of glottal stop and [h] in Dutch words is conditioned by the left edge of a foot (see (8a)). However, if Reduction Domains are equated with embedded feet, then immediately post-tonic unstressed full vowel syllables should have a foot boundary before them, since full vowel syllables must be the head of their own Reduction Domain (see (8b)). This would predict the occurrence of glottal stop and $[\mathrm{h}]$ in exactly the position in which is it banned (see $(8 \mathrm{c}))$.

(8)
a. ('ta.o) *('ta.?o) 'Tao'
('fa.ra)(, ?o) 'pharaoh'
data from Kager \& Martínez-Paricio (2014)
('sa.It) *('sa.?it) 'Said (name)' ('efra)( , PIm) 'Ephraim'
b. $\left({ }^{\prime}<\mathrm{ta}>.<\mathrm{O}>\right) \quad$ since $[\mathrm{o}]$ is a full vowel syllable
('(ta)(o)) if Reduction Domains are equated with embedded feet
c. *('(ta)(?o)), *('(sa)(?It)) cannot be ruled out if every full vowel syllable heads its own foot

For this reason, I will not consider the Reduction Domain to be an instance of recursive footing, but rather as a separate prosodic category, falling in between the syllable and the foot (see section 4 for some speculations on how the Reduction Domain might fit into a theory of prosodic domains). This solution appears rather bold at first sight, but it seems to trump at least two viable alternative solutions that come to mind.

One alternative option to account for the morphotactics of verb and adjective roots would be to stipulate that there is a constraint that mandates vowel reduction in verb and adjective roots: 
LIC-FullV/Stress $\mathrm{Verb}_{\text {Adj-Root }}$ : One violation mark for every full vowel inside a verb or adjective root which is in an unstressed position. (Licensing format taken from Crosswhite 1999)

This is a very inelegant solution, especially given that derivational suffixes with full vowels may attach to verb and adjective roots (for instance, [bitər-heid] *[bitər-(h)əd] 'bitterness'; [stotər-ar] *[stotər-ər] 'stutterer'), so that this vowel reduction constraint would apply to at most one unstressed vowel in a word.

Another alternative option would be to assume a constraint which features a detailed template:

Verb/Adjective-Root $={ }^{\prime} \sigma \quad(\sigma):$ One violation mark if a verb or adjective root does not follow the fullV $\partial$ template "full vowel syllable plus (optionally) a schwa syllable".

This option is also conceivable, but goes against the drive typical for OT analyses to decompose complex phonological effects into the interaction of simple constraints. As shown in section 3 below, Reduction Domains are not only useful for accounting for morphotactics, but also provide an account of restrictions on vowel reduction in the same language. This strengthens the point for seeing the morphotactics facts presented in the current section as the interaction of the existence of Reduction Domains, and the existence of a high-ranked constraint which mandates that verb/adjective roots fit into a Reduction Domain.

\section{Vowel reduction}

Vowel reduction in Dutch is optional, and conditioned by many different factors, including lexical identity, word frequency, syllable structure, and underlying vowel quality (Kager 1989, Booij 1995). However, independently of these factors, a rhythmical restriction exists.

In a sequence of a stressed syllable followed by two unstressed syllables ${ }^{1}$, reduction of both unstressed syllables is possible, as is reduction of just the second syllable of the sequence. However, reduction of just the third syllable in the sequence is not possible (Kager 1989, van Oostendorp 1995, Booij 1995):

(9)

,fonolo'yi (no reduction) ,fonələ 'yi (full reduction) ,fonəlo'yi (partial reduction) 'phonology'

* fonolə 'yi (ungrammatical partial reduction)

This restriction has a non-trivial interaction with vowel quality, which will be discussed in section 3.2. However, for now I will present an account of just this positional restriction on vowel reduction.

3.1 An account in terms of Reduction Domains Given the definition of Reduction Domains (RDs) in section 2, the division of a string into Reduction Domains is determined by which vowels are schwa on the surface (since every full vowel must head its own Reduction Domain). This means that reduced and non-reduced variants of one and the same word will receive different parses:

(10) Reduction Domain parses for /fonolo' yi/

a. $\left(,<\mathrm{fo}_{\mathrm{o}}>\mathrm{no}>\right)<\mathrm{lo}>\left({ }^{\prime}<\mathrm{\gamma i}>\right) \quad$ no reduction: $R D$ over each syllable

b. $\left({ }_{1}<\right.$ fon $\left.>>\right)<10>('<\mathrm{yi}>) \quad$ partial reduction: binary $R D$ in binary foot, unary $R D$ s elsewhere

c. $(<$ fonə $>)$ lo $\left({ }^{\prime}<\mathrm{\gamma i}>\right) \quad$ full reduction: no unary $R D$ s on non-final syllables

It is this variability in parsing that makes Reduction Domains useful to explain vowel reduction. I propose that partial reduction (as in (10b)) is triggered by a well-established constraint: the Stress-to-Weight Principle (SWP; Prince 1990, Gouskova 2003:90 and work cited there). The SWP is usually invoked to motivate the phenomenon of syllable augmentation - stressed syllables receive extra material (usually, a vowel is lengthened) to make them heavy. Formally, the OT constraint SWP may be interpreted as follows

\footnotetext{
${ }^{1}$ The stressed syllable in these cases always has secondary rather than primary stress, because primary stress cannot be followed by more than one unstressed syllable in a row (see Kager 1989 for discussion of primary and secondary stress in Dutch).
} 
(see Gouskova 2003:90 and work cited there for various formulations of the constraint):

SWP: One violation mark whenever the head position of a foot is filled by a non-branching structure.

When there is no level in between feet and syllables, this means that SWP requires stressed syllables to be branching at the level of the mora (which may lead to syllable augmentation).

(11) SWP violations when there is no Reduction Domain between feet and syllables

a. SWP-violating structure<smiles>COC(C)O</smiles>

b. SWP-conforming structure<smiles>CCOC(C)(C)C</smiles>

However, when the direct dependent of the foot is the Reduction Domain, then SWP may be interpreted as a requirement that Reduction Domains that are in the head position of a Foot branch in terms of syllables:

(12) SWP violations when there are Reduction Domains between feet and syllables

a. SWP-violating structure

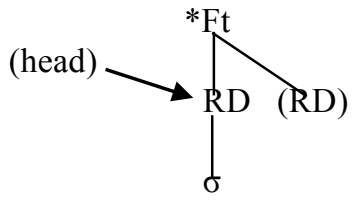

b. SWP-conforming structure

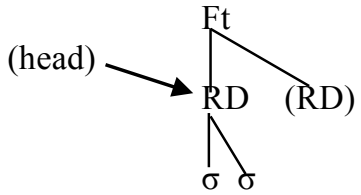

This extension of SWP to Reduction Domains (which happens automatically whenever RDs are present) has an interesting consequence: it means that it is possible to satisfy SWP by parsing two syllables instead of one into the same Reduction Domain. For instance, when the stressed syllable [fo] in [,fonolo' yi] is in its own Reduction Domain (as in (10a)), this constitutes a violation of SWP, since the foot $(<<\mathrm{fo}><$ no $>)$ does not have a binary Reduction Domain in its head position. On the other hand, when the unstressed post-tonic syllable [no] in [,fonolo'yi] is reduced to [nə], as in (10b), the foot $(<$ fonə>) contains no violations of SWP, since the Reduction Domain $<$ fona $>$ which is in the head position of that foot has two syllables in it.

This means that SWP can motivate vowel reduction, as shown in (13a). In these tableaux, SWP is ranked above the faithfulness constraint $\operatorname{Ident}(\mathrm{V})$ :

Ident(V): One violation mark for every vowel which is not identical to its corresponding input segment.

(13)

a. reduction in immediately post-tonic position

\begin{tabular}{|l|l|l|}
\hline$/$ fonoloyi/ & SWP & $\operatorname{Ident}(\mathrm{V})$ \\
\hline$(,<$ fo $><$ no $>)<\mathrm{lo}>\left({ }^{\prime}<\mathrm{\gamma i}>\right)$ & ${ }^{\prime}<$ fo $>$; ${ }^{\prime}<\mathrm{\gamma i}>$ ! & \\
\hline$(,<$ fo.nə $>)<\mathrm{lo}>\left({ }^{\prime}<\mathrm{\gamma i}>\right)$ & ${ }^{\prime}<\mathrm{\gamma i}>$ & $*$ \\
\hline
\end{tabular}

\begin{tabular}{|l|l|l|}
\hline$/$ filosof/ 'philosopher' & SWP & Ident(V) \\
\hline$(,<$ fi $><$ lo $>)('<$ sof $>)$ & ${ }^{\prime}<$ fi $>$; $<$ sof $>$ ! & \\
\hline$\left(,<\right.$ fi.ləə>) $\left({ }^{\prime}<\right.$ sof $\left.>\right)$ & ${ }^{\prime}<$ sof $>$ & $*$ \\
\hline
\end{tabular}

b. lack of reduction outside immediately post-tonic positions

\begin{tabular}{|l|l|l|}
\hline$/$ tomat $/$ 'tomato' & SWP & $\operatorname{Ident}(\mathrm{V})$ \\
\hline to $($ ' $<$ mat $>$ ('< $)$ & $1<$ mat $>)$ & \\
\hline
\end{tabular}

However SWP alone is not sufficient to cover all instances of reduction, as shown in (13b) above. Reduction of vowels that are not immediately post-tonic does cannot serve to satisfy SWP. To account for the fact that all unstressed syllables can potentially reduce in Dutch, I assume that there is also a general- 
purpose reduction constraint, LIC-FullV/Stress (inspired by Crosswhite's (1999) reduction-motivating positional licensing constraints), which penalizes any unstressed full vowel.

LIC-FullV/Stress: One violation mark for every unstressed full vowel.

If SWP and Ident $(\mathrm{V})$ are combined with LIC-FullV/Stress, then re-ranking of these constraints yields the full spectrum of variation for /fonoloyi/, as is shown in tableaux (14-16).

(14) Tableau 1: Ident $(V)>>$ SWP, LIC-FullV/Stress yields no reduction

\begin{tabular}{|c|c|c|c|}
\hline /fonoloyi/ & $\operatorname{Ident}(\mathrm{V})$ & SWP & LIC-FullV/Stress \\
\hline$(,<$ fo $><$ no $>)<$ lo $>\left({ }^{\prime}<\right.$ yi $\left.>\right)$ & & $* *$ & $* *$ \\
\hline$(,<$ fon $>>)<\mathrm{lo}>\left({ }^{\prime}<\mathrm{yi}>\right)$ & $* !$ & $*$ & * \\
\hline$(,<$ fo $><$ no $>)$ lo $\left({ }^{\prime}<\mathrm{yi}>\right)$ & $* !$ & $* *$ & * \\
\hline$(,<$ fonə $>)$ lə $\left({ }^{\prime}<\right.$ yi $\left.>\right)$ & $* ! *$ & * & \\
\hline
\end{tabular}

In this tableau, Ident $(\mathrm{V})$ is the highest-ranking constraint, and the candidate which is chosen is the one which does not violate this constraint, which is the unreduced candidate.

(15) Tableau 2: SWP $>>$ Ident $(V)>>$ LIC-FullV/Stress yields reduction in post-tonic positions only

\begin{tabular}{|c|c|c|c|}
\hline /fonoloyi// & SWP & Ident(V) & LiC-FullV/Stress \\
\hline$(,<\mathrm{fo}><\mathrm{no}>)<\mathrm{lo}>\left({ }^{\prime}<\mathrm{\gamma i}>\right)$ & $* * !$ & & ** \\
\hline$(,<$ fono $>)<$ lo $>\left({ }^{\prime}<\right.$ yi $\left.>\right)$ & * & * & * \\
\hline$(,<$ fo $><$ no $>)$ lo $\left({ }^{\prime}<\right.$ yi $\left.>\right)$ & $* * !$ & $*$ & * \\
\hline$(,<$ fonə>) lə $('<\gamma \mathrm{i}>)$ & * & $* * !$ & \\
\hline
\end{tabular}

In this tableau, SWP ranks highest, and the candidates without immediately post-tonic reduction are ruled because they have an extra violation of SWP. Of the two remaining candidates, the one with the least violations of $\operatorname{Ident}(\mathrm{V})$ is chosen: the candidate with reduction of just the immediately post-tonic syllable.

(16) Tableau 3: LIC-FullV/Stress $>>$ SWP, Ident(V) yields reduction in all unstressed syllables

\begin{tabular}{|c|c|c|c|}
\hline /fonoloyi/ & LiC-FullV/Stress & SWP & $\operatorname{Ident}(\mathrm{V})$ \\
\hline$(,<$ fo $><$ no $>)<$ lo $>\left({ }^{\prime}<\mathrm{yi}>\right)$ & $* ! *$ & $* *$ & \\
\hline$(,<$ fon $ə>)<\mathrm{lo}>\left({ }^{\prime}<\mathrm{yi}>\right)$ & $* !$ & $*$ & : \\
\hline$(,<$ fo $><$ no $>)$ lo $\left({ }^{\prime}<\mathrm{yi}>\right)$ & $* !$ & $* *$ & * \\
\hline$(,<$ fonə $>)$ lə $('<\mathrm{yi}>)$ & & $*$ & ** \\
\hline
\end{tabular}

In this tableau, LIC-FullV/Stress is the highest-ranking constraint, and the candidate which does not violate this constraint - which is the fully reduced candidate - is chosen as the winner.

Crucially, there is no motivation to reduce just the third syllable in the dactylic sequence [,fonolo]. SWP is in favor of reducing the second syllable in the dactylic sequence, while Lic-FullV/Stress is in favor of reducing both unstressed syllables in the sequence. As all three tableaux in (14-16) show, the third candidate, which is the ungrammatical variant *[,fonola' yi], has a superset of the violations of the second candidate, [, fonəlo' vi]. This means that the ungrammatical variant is harmonically bounded, and will never win under any ranking of these three constraints.

Thus, SWP is instrumental in accounting for partial vowel reduction in Dutch and its distribution (only immediately post-tonic vowels reduce in a partial reduction scenario). Two simple and well-established constraints, Ident(V) and a general-purpose constraint against unstressed vowels, generate just the range of variation observed for Dutch vowel reduction when allowed to be variably ranked with respect to SWP. 
Accounts of the same data have been given by van Oostendorp (1995) and De Lacy $(2002)^{2}$. Their accounts rely on the notion that the third syllable in a dactylic sequence has a stronger prosodic position than the second syllable. For van Oostendorp (1995), the third syllable of a dactylic sequence is the head of a (stressless) unary foot; De Lacy (2002) assumes that the third syllable of a dactylic sequence is unfooted.

(17) Foot structures assumed by van Oostendorp (1995) and De Lacy (2002)

a. van Oostendorp (1995): (, fono) (1o) ('yi)

b. De Lacy (2002): (, fono) lo ('yi)

Both accounts assume that there are constraints that penalize all unstressed full vowels (similar to LICFullV/Stress in the current account). Van Oostendorp also assumes a separate constraint which penalizes full vowels outside foot heads, which motivates reduction in the second syllable of a dactylic sequence, given the representation in (17a). De Lacy assumes a constraint which penalizes full vowels in the dependent position of a foot, which has a similar effect: it triggers reduction in just the immediately posttonic position.

In this way, van Oostendorp and De Lacy both have a constraint which motivates full reduction (parallel to LIC-FullV/Stress), and a constraint which motivates reduction in post-tonic positions (parallel to SWP), but there is no motivation for reduction in the third syllable of a dactylic sequence, so that ungrammatical *[, fonolə' yi] is always harmonically bounded.

Van Oostendorp's and De Lacy's accounts are both based on the idea that unstressed syllables outside of strictly binary feet are always stronger than unstressed syllable which are inside a binary foot (see (18a)). However, Martínez-Paricio (2013) shows that there are cases in which unstressed syllables outside a strictly binary foot are actually weaker than unstressed syllables which are inside a binary foot. She shows cases in which, by contrast, it is the syllable inside the binary foot that is stronger than the syllable outside the binary foot (see (18b)).

(18)

a. The world according to van Oostendorp's (1995) and De Lacy's (2002) theories

$\left(\sigma_{1} \sigma_{2}\right) \sigma_{3}(' \sigma \sigma)$

All languages: $\sigma_{3}$ is stronger than $\sigma_{2}$

b. Updated worldview based on Martinez-Paricio's (2013) findings

$\left(\sigma_{1} \sigma_{2}\right)\left(\sigma_{3}(' \sigma \sigma)\right) \quad$ or $\quad\left(\sigma_{1} \sigma_{2}\right) \sigma_{3}(' \sigma \sigma)$

Language type 1: $\sigma_{3}$ is stronger than $\sigma_{2}$

Language type 2: $\sigma_{2}$ is stronger than $\sigma_{3}$

This is a problem for both van Oostendorp's (1995) and De Lacy's (2002) accounts, which rely on the inherent strength of syllables outside the binary foot. Martínez-Paricio (2013) argues for separate constraints which prefer reduction inside a binary foot (in her terminology: reduction of a Minimal Foot dependent), and ones which prefer reduction outside a binary foot (in her terminology: reduction of a NonMinimal Foot dependent). The Dutch facts are obtained by ranking a constraint against full vowels in Minimal Foot dependents above a constraint against full vowels in Non-Minimal Foot dependents.

(19) The crucial ranking in Martinez-Paricio's (2013) account for the generalization in (9)

a. *Non-Head(MinFoot)/a, e•o, i•u: One violation mark for any high, mid, or low non-schwa vowel which is in the dependent position of a Minimal Foot. Penalizes [o] in the syllable [no] in (, fo *no ) (lo ('yi)).

*Non-Head(NonMinFoot)/a, e•o, i•u: One violation mark for any high, mid, or low non-schwa vowel which is in the dependent position of a Non-Minimal Foot. Penalizes [o] in the syllable [lo] in (, fono) ( *lo ('yi)).

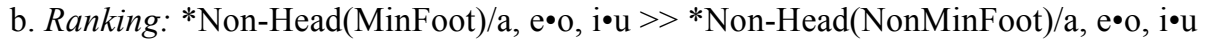

A similar account is proposed by Geerts (2008), who assumes a ranking of positional faithfulness

${ }^{2}$ Other OT accounts of these data have been given by van Oostendorp (1997b), Geerts (2008), and Martínez-Paricio (2013). 
constraints which protect vowels from reduction:

a. Ident(V)-Unfooted ${ }^{3}$ : One violation mark for every unfooted vowel which is non-identical to its corresponding input segment.

Ident(V)-Footweak: One violation mark for every vowel in the weak position of a foot which is non-identical to its corresponding input segment.

b. Ranking: Ident(V)-Unfooted $>>$ Ident(V)-Footweak

The Reduction Domain account also avoids the problem of relying on the idea of a binary foot-internal unstressed syllable being weaker than a binary foot-external one, because the SWP account of partial reduction does not directly rely on footing, but rather on stress placement. The reason why binary footinternal syllables are reduced while binary foot-external syllables may retain their underlying vowel quality at the same time is because it is only binary foot-internal syllable which can help create a binary Reduction Domain in stressed position, as shown in (21):

a. $(<$ fon $>>)<$ lo $>('<\mathrm{yi}>)$ has fewer violations of SWP than $(,<$ fo $><$ no $>)<$ lo $>\left({ }^{\prime}<\mathrm{yi}^{\prime}>\right)$, since the stressed Reduction Domain $<$ fon $>>$ is binary (contains two syllables).

b. $(,<$ fo $><$ no $>)$ lə $\left({ }^{\prime}<\mathrm{yi}>\right)$ has the same number of violations of SWP as $(,<$ fo $><$ no $>)<$ lo $>('<$ i $>)$, since the stressed Reduction Domain $<$ fo $>$ has just one syllable in both candidates.

Martínez-Paricio (2013) and Geerts (2008) account for the restriction in (9) by stipulating that reduction in binary foot-internal position simply happens to be more preferred than reduction in binary foot-external positions. The SWP approach makes the same data fall out from two independently motivated phenomena (Reduction Domains and the Weight-to-Stress Principle), which can be seen as a more elegant and principled solution.

However, ultimately the decision between Martínez-Paricio (2013) and Geerts (2008) on the one hand, and the current SWP approach on the other hand, should be made on empirical grounds, and there are at least two empirical prediction which the SWP approach makes that differ from the predictions of MartínezParicio's (2013) and Geerts' (2008) accounts.

My approach predicts that, if a language provides evidence for a Reduction Domain and allows partial vowel reduction (i.e., not all unstressed vowels in the word are reduced) targets either the position inside the binary foot or all unstressed syllables (as it does in Dutch), but never just the position outside the binary foot. On the other hand, Martínez-Paricio (2013) and Geerts (2008) predict that, even if there is evidence for a Reduction Domain, vowel reduction could still prefer the position outside the binary foot. In other words, the SWP approach predicts the impossibility of a language like the one described in (22). It is not clear whether such a language is impossible (the languages that preferably affect the position outside the binary foot mentioned by Martínez-Paricio (2013) seem to be of a different kind), but this is a question for future research.

(22) Language deemed impossible by SWP approach to reduction

a. Reduction Domains are present

$(<$ ta $><\mathrm{ka}>)<$ ma $>('<\mathrm{la}><\mathrm{bi}>)$

b. Partial vowel reduction is possible, but only outside binary feet

$(<$, $\mathrm{ta}><\mathrm{ka}>)$ mə $\left({ }^{\prime}<\mathrm{la}><\mathrm{bi}>\right) \quad *(<$, ta.kə $>)<$ ma $>\left({ }^{\prime}<\mathrm{la}><\mathrm{bi}>\right)$

Another empirical prediction only made by the SWP approach and not by Martínez-Paricio (2013) and Geerts (2008) is that the differences in prosody between reduced and unreduced forms of the same word, assumed in the SWP account of vowel reduction, are likely to bring along other changes as well. Prosodic domains often condition phonological processes or phonotactic (im)possibilities. For instance, Kager \&

${ }^{3}$ Geerts (2008) calls these constraints Max-IO-Unfooted and Max-IO-Footweak, respectively, assuming that vowel reduction means deletion of features. However, these constraints perform the exact same function as Ident(V) constraints in my account, which is why I renamed them to Ident(V)-Unfooted and Ident(V)-Footweak. 
Martínez-Paricio (2014) show that the occurrence of glottal stop and [h] in Dutch are dependent on foot structure, so that changing the foot structure of a word would mean a different distribution of glottal stop and [h]. In a similar fashion, some other segmental process (other than vowel reduction) could depend on Reduction Domain boundaries, and one would predict that the application of that processes co-varies with vowel reduction. So far, it is not clear what process this should be, but this is also an important topic for future research ${ }^{4}$.

Thus, SWP provides an elegant account of the positional restriction on vowel reduction ((9)), while also making novel empirical predictions. I will now turn to the interaction of vowel quality and prosodic position, to show that the SWP story can indeed account for the full range of Dutch vowel reduction facts.

3.2 Interaction of vowel quality and position As was briefly mentioned in section 2.1, there is a systematic exception to the positional generalization stated in (9). This exception has to do with vowel quality, which interacts with vowel reduction in several ways: certain vowels are more prone to being available for reduction (across lexical items), and certain vowels are allowed to reduce in more formal registers than other vowels (Kager 1989, Booij 1995, Oostendorp 1995). Kager (1989) has found that both types of evidence converge on the following hierarchy of vowels, from most reducible to least reducible:

\section{(23) Kager's (1989) hierarchy of vowels from most reducible to least reducible ${ }^{5}$}

$\mathrm{e}>\mathrm{a}>\mathrm{o}, \varnothing>\mathrm{i}>\mathrm{u}, \mathrm{y}$

The vowel quality hierarchy interacts with the generalization, stated in (9), that the third vowel in a dactylic sequence may not reduce without the second vowel in that same dactylic sequence reducing. Whenever the third vowel of a dactylic sequence is higher on the reducibility hierarchy than the second vowel, then this third vowel may reduce without the second vowel also reducing. This is schematized in the diagram below:

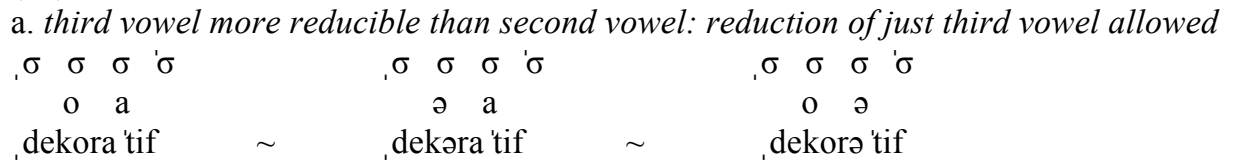

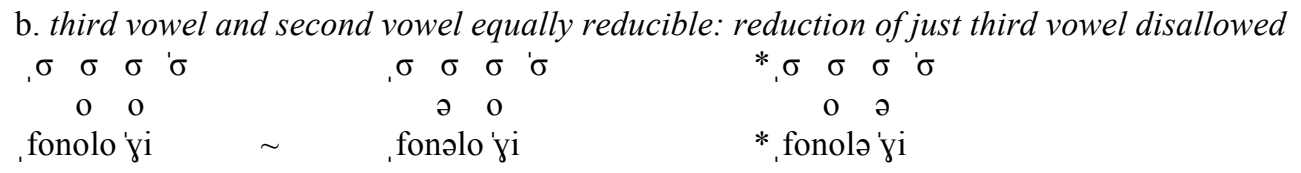

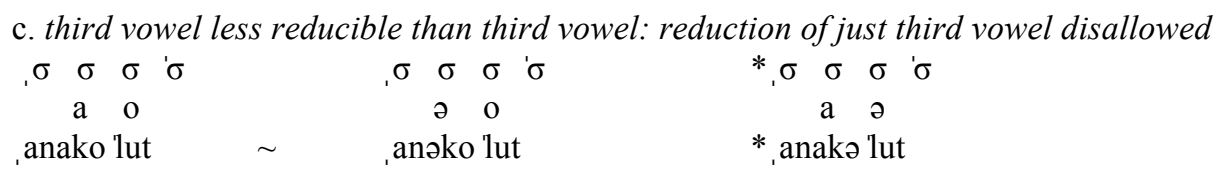

Van Oostendorp $(1995,1997 b)$ proposes to implement Kager's hierarchy in the form of a ranking of faithfulness constraints, which is shown here in a slightly modified version:$$
\operatorname{Ident}([\text { high }])>>\operatorname{Ident}([\operatorname{round}])>>\operatorname{Ident}([\text { low }])>>\operatorname{Ident}(V)^{6}
$$

I assume with van Oostendorp (1995) that phonological features are unary rather than binary, so that for a vowel like /o/, the constraints Ident([high]) and Ident([low]) will not be violated when /o/ maps to [ə], since /o/ only has a marked value for [round], not for [high] or [low]. For a vowel like /i/, on the other hand,

\footnotetext{
${ }^{4}$ Many thanks to René Kager (p.c.) for pointing this out.

${ }^{5}$ Booij (1995) gives a different hierarchy, but Kager's (1989) hierarchy appears to be based on a richer array of data.

${ }^{6}$ Van Oostendorp assumes that the vowel/e/ is the only vowel which has the feature [coronal], which is why the lowest constraint in the original version of this ranking is Ident(coronal).
} 
Ident([high]) will be violated for the mapping /i/ $\rightarrow$ [ə], but not Ident([round]) or Ident([low]).

If the constraints that trigger reduction (SWP and LIC-FullV/Stress) may be ranked variably with respect to the constraints in (25), this perfectly captures the interaction between vowel quality and reduction (see also van Oostendorp 1995, 1997b).

When the second and third vowels in a dactylic sequence are identical, there is only one faithfulness constraint which decides their behavior, which is the highest of the constraints in (25) which applies to that vowel. For instance, for /o/ this is Ident([round]). There is no ranking of Ident([round]), Ident([low]), SWP, and LIC-FullV/Stress which would lead to reduction in just the third syllable of a dactylic sequence when both unstressed vowels in the sequence are /o/: the third, ungrammatical candidate in the tableau below is harmonically bounded by the second candidate.

(26)

\begin{tabular}{|c|c|c|c|c|}
\hline /fonoloyi/ & Ident $([$ round $])$ & $\begin{array}{l}\operatorname{Ident}([\mathrm{low}]) \\
\end{array}$ & SWP & $\begin{array}{l}\text { LiC-FullV/Stress } \\
\end{array}$ \\
\hline$\left({ }_{1}<\mathrm{fo}><\mathrm{no}>\right)<\mathrm{lo}>\left({ }^{\prime}<\mathrm{\gamma i}>\right)$ & & & ** & :** \\
\hline$(,<$ fonə $>)<$ lo $>\left({ }^{\prime}<\mathrm{\gamma i}>\right)$ & $*$ & & : & : \\
\hline$(,<$ fo $><$ no $>)$ lə $\left({ }^{\prime}<\right.$ yi $\left.>\right)$ & $*$ & & ** & ; \\
\hline 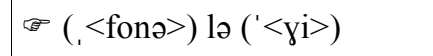 & $* *$ & & : & \\
\hline
\end{tabular}

However, whenever the third vowel in the dactylic sequence is higher on the reducibility hierarchy than the second vowel, there is a constraint ranking which yields reduction of just that third vowel. This is when the highest faithfulness constraint relevant to the third vowel is ranked above both SWP and LIC-FullV/Stress, while the highest faithfulness constraint relevant to the second vowel is ranked below LIC-FullV/Stress.

For instance, when the third syllable of a dactylic sequence has the vowel /a/, while the second syllable has the vowel /o/, then the ranking Ident([round]) $>>$ SWP, LIC-FullV/Stress $>$ Ident([low]) will yield reduction of just the /a/. This is shown in the tableau below:

\begin{tabular}{|c|c|c|c|c|}
\hline /dekoratif/ & Ident $([$ round $])$ & SWP & LiC-FullV/Stress & $\operatorname{Ident}([$ low $])$ \\
\hline$(,<\mathrm{de}><\mathrm{ko}>)<\mathrm{ra}>\left({ }^{\prime}<\mathrm{tif}>\right)$ & & $* *$ & $* *$ & \\
\hline$(,<$ dekə $>)<$ ra $>\left({ }^{\prime}<\right.$ tif $\left.>\right)$ & $* !$ & * & : & \\
\hline$(,<\mathrm{de}><\mathrm{ko}>) \mathrm{r} ə\left({ }^{\prime}<\mathrm{tif}>\right)$ & & $* *$ & : & * \\
\hline$(,<$ dekə>) rə $('<$ tif $>)$ & $* !$ & * & & * \\
\hline
\end{tabular}

High-ranked Ident([round]) eliminates the candidates in which /o/ is reduced. Since LIC-FullV/Stress is ranked above Ident([low]), the grammar prefers the remaining candidate which reduces unstressed /a/. Thus, reduction in just the third syllable wins under this particular ranking.

When the more reducible vowel is in the second rather than the third syllable of the dactylic sequence, the same ranking does not produce reduction in just the third syllable, as shown in the tableau below. Reduction in just the third syllable of such words would require for Ident([low]) to dominate Ident([round]), but this is precluded by the ranking in (25).

(28)

\begin{tabular}{|c|c|c|c|c|}
\hline /anakolut/ & Ident([round] $)$ & SWP & $\begin{array}{l}\text { LiC-FullV/Stress } \\
\text { L }\end{array}$ & $\operatorname{Ident}([$ low $])$ \\
\hline$(,<\mathrm{a}><\mathrm{na}>)<\mathrm{ko}>\left({ }^{\prime}<\mathrm{lut}>\right)$ & & $* * !$ & ** & \\
\hline$\circledast(,<$ anə $>)<\mathrm{ko}>\left({ }^{\prime}<\mathrm{lut}>\right)$ & & $*$ & : & $*$ \\
\hline$(,<\mathrm{a}><$ na $>) \mathrm{k} ə\left({ }^{\prime}<\right.$ lut $\left.>\right)$ & $* !$ & $* *$ & * & \\
\hline$\left(,<\right.$ anə>) kə $\left({ }^{\prime}<\right.$ lut $\left.>\right)$ & $* !$ & * & & $*$ \\
\hline
\end{tabular}


In this tableau, high-ranked Ident([round]) rules out reduction in the third syllable, while the low ranking of Ident([low]) results in reduction in the second syllable. The only constraint that favors * [anaks'lut] is Ident([low]), which would have to be ranked above Ident([round]) in order to make *[, anakə'lut] win - but the ranking in (25) would not allow this.

In short, I have shown in this section that the positional restriction on partial reduction may be motivated by SWP. This particular account has several advantages over existing approaches, but the Reduction Domain is necessary in order to make this account work. Finally, I have shown that this approach can also deal with systematic exceptions to the positional restriction on partial reduction.

\section{Concluding remarks}

In this paper, I have proposed a new prosodic category between the foot and the syllable: the Reduction Domain. Motivated by facts of Dutch, this prosodic category has full vowels as heads, and reduced syllables as dependents. I proposed that facts of morphotactics motivate this prosodic domain. Underived verb and adjective stems show a strong tendency to be confined to precisely one Reduction Domain, a restriction which is supported by psycholinguistic work (Don \& Erkelens 2006).

Furthermore, I have shown that Reduction Domains provide an account for the positional restriction on partial vowel reduction in Dutch. When a word has a dactylic sequence (strong-weak-weak), the third vowel in that sequence may only reduce if the second vowel in the sequence is also reduced (for instance, /fonoloyi/ $\rightarrow$ [,fonəlo'yi], *[,fonolə' yi]). If Reduction Domains are present, the positional restriction on reduction follows from activity of the constraint SWP, because, apart from syllable augmentation, SWP can also motivate the presence of a binary Reduction Domain (as explained in section 3.1). A binary Reduction Domain that contains a stressed syllable entails reduction in immediately post-tonic position. If SWP is ranked variably with respect to a constraint against all unstressed full vowels, as well as the constraint Ident $(\mathrm{V})$, then three options of reduction emerge (reduction of all vowels, reduction of immediately posttonic vowels, no reduction), while reduction of just the third syllable in a dactylic sequence is ruled out.

One of the most important questions that this account raises is the status of the Reduction Domain in a theory of prosodic domains (Nespor \& Vogel 1986, Selkirk 1986). One option would be to maintain that the Reduction Domain is a prosodic domain available universally in all languages. While this is possible, the first question would be why it is not the case that every language provides ample evidence of Reduction Domains. Also, assuming that the Reduction Domain is universal would require some minor adjustments to the account given here (see examples (11-12) and (22) in section 3.1).

Another option would be that Reduction Domains are an instantiation of some established representational level. As was pointed out in section 2, it is unlikely that Reduction Domains could be a foot-type domain, because minimal and maximal feet have other functions in the same language, as pointed out by Martínez-Paricio (2013) and Kager \& Martínez-Paricio (2014). However, perhaps the Reduction Domain could be thought of as some kind of extended syllable, which is in line both with previous work about Dutch morphotactics (Trommelen 1989), and with the SWP approach to partial vowel reduction taken in this paper. This option should be elaborated in future work on this topic.

A third option would be that Reduction Domains are available in some languages, but not others. The presence or absence of Reduction Domain could be analogous to the presence or absence of tone tiers in a language: they are available whenever the data provide strong enough evidence for them. "Strong enough evidence", of course, is a term that is itself in need of definition. However, the progress that has been made in hidden structure learning (Tesar \& Smolensky 2000, Boersma \& Pater 2008, Jarosz 2013) gives hope that it will soon be possible to evaluate this evidence in a precise, computational manner. It is this third option that I have assumed here for convenience, but more research is possible to decide between analyses.

Another important question is what other phenomena Reduction Domains might be able to explain. One such phenomenon could be sesquisyllabicity (Matisoff 1973). In sesquisyllabic languages (of which Burmese is an example; Butler 2014), words may consist of one full syllable, preceded by a "reduced" syllable (signs of reduction may include no tone, no full vowels, or a reduced coda inventory; see Butler 2014). This pattern could perhaps be captured with a right-headed Reduction Domain, but more research is necessary to make a definite claim about this.

Finally, the empirical predictions of the SWP approach pointed out at the end of section 3.1 warrant further investigation. One prediction is a typological one: the SWP approach implies that there should be no languages where there is evidence for a Reduction Domain, but vowel reduction preferably occurs outside the (minimal) foot. Another prediction is that if there are any segmental processes tied to the Reduction 
Domain, the application of these processes should vary between reduced and unreduced variants of the same word.

Thus, Reduction Domains are an interesting puzzle both in the context of Dutch phonology and for the theory of prosodic domains, and much interesting work is to be done in the future.

\section{References}

Bennett, Ryan. 2013. 'The uniqueness of metrical structure: rhythmic phonotactics in Huariapano'. Phonology, 30, 3 , 355-398.

Boersma, Paul \& Joe Pater. 2008. 'Convergence properties of a Gradual Learning Algorithm for Harmonic Grammar'. Ms., University of Amsterdam \& University of Massachusetts, Amherst.

Booij, Geert. 1995. The phonology of Dutch. Oxford: Clarendon Press.

Booij, Geert. 2002. The morphology of Dutch. Oxford: Oxford University Press.

Butler, Becky. 2014. Deconstructing the Southeast Asian sesquisyllable: A gestural account. Doctoral dissertation. Cornell University.

Crosswhite, Katherine. 1999. Vowel reduction in Optimality Theory. Doctoral dissertation, University of California, Los Angeles.

De Lacy, Paul. 2002. The formal expression of markedness. Doctoral dissertation, University of Massachusetts, Amherst.

Don, Jan \& Marian Erkelens. 2006. 'Vorm en Categorie'. Taal en Tongval, 19, 40-54.

Geerts, Twan. 2008. More about Less. Fast Speech Phonology: the Cases of French and Dutch. Doctoral dissertation, Radboud University of Nijmegen.

Gouskova, Maria. 2003. Deriving economy: Syncope in Optimality Theory. Doctoral dissertation, University of Massachusetts, Amherst.

van der Hulst, Harry G. \& Michaël Moortgat. 1980. 'Prosodische fonologie en de accentuatie van Nederlandse woorden, of: Leeft het Nederlands op grote voet?'. In: Verslag van de 150e vergadering van de Vereniging van Fonetische Wetenschappen, 1-25.

Jarosz, Gaja. 2013 'Learning with Hidden Structure in Optimality Theory and Harmonic Grammar: Beyond Robust Interpretive Parsing'. Phonology, 30, 1, 27-71.

Kager, René W.J. 1989. A Metrical Theory of Stress and Destressing in English and Dutch. PhD dissertation, Utrecht University.

Kager, René W.J. \& Violeta Martínez-Paricio. 2014. The internally layered foot in Dutch word prosody. Talk given at the 'Aspects of Germanic Phonology' Workshop, Oxford (UK), September 6-8, 2014.

Liberman, Mark \& Alan Prince. 1977. 'On stress and linguistic rhythm'. Linguistic Inquiry, 8, 249-336.

Martínez-Paricio, Violeta. 2013. An exploration of minimal and maximal metrical feet. PhD Dissertation, University of Tromsø.

Matisoff, James A. 1973. 'Tonogenesis in Southeast Asia'. In: Larry M. Hyman (Ed.), Consonant types \& tones, LA: USC, pp. 71-95.

McCarthy, John J. 2005. 'Optimal paradigms'. In: Laura Downing, Tracy Alan Hall \& Renate Raffelsiefen (eds.), Paradigms in Phonological Theory, Oxford: Oxford University Press, pp. 170-210.

Nespor, Marina, and Irene Vogel. 1986. Prosodic Phonology. Dordrecht: Foris.

van Oostendorp, Marc. 1995. Vowel Quality and Syllable Projection. Doctoral dissertation, Catholic University of Brabant.

van Oostendorp, Marc. 1997a. 'Lexicale variatie in de optimaliteitstheorie'. Nederlandse Taalkunde, 2, 133-154.

van Oostendorp, Marc. 1997b. 'Style levels in conflict resolution'. In: Frans Hinskens, Roeland van Hout, Leo Wetzels (eds.), Language variation and linguistic theory, Amsterdam: John Benjamins, pp. 207-229.

Pater, Joe. 2000. 'Non-uniformity in English secondary stress: the role of ranked and lexically specific constraints'. Phonology, 17, 237-274.

Prince, Alan. 1990. 'Quantitative Consequences of Rhythmic Organization'. In: Karen Deaton, Manuela Noske, and Michael Ziolkowski (eds.), CLS 26-II: Papers from the Parasession on the Syllable in Phonetics and Phonology, Chicago: Chicago Linguistics Society, pp. 355-398.

Prince, Alan \& Paul Smolensky. 1993/2004. 'Optimality Theory: Constraint interaction in generative grammar'. Technical report, Rutgers University and University of Colorado at Boulder, 1993. ROA 537, 2002. Revised version published by Blackwell, 2004.

Selkirk, Elizabeth O. 1980. 'The role of prosodic categories in English word stress'. Linguistic Inquiry, 11, 3, 563-605.

Selkirk, Elizabeth O. 1986. 'On derived domains in sentence phonology'. Phonology, 3, 371-405.

Tesar, Bruce \& Paul Smolensky. 2000. Learnability in Optimality Theory. Cambridge, MA: MIT Press.

Trommelen, Mieke. 1989. 'Lettergreepstruktuur en woordkategorie'. De Nieuwe Taalgids, 82, 64-77. 